\title{
The scale of VGI in map production: A perspective of European National Mapping Agencies.
}

Ana-Maria Olteanu-Raimond*, ${ }^{\text {, Glen Hart }}{ }^{2}$, Giles M. Foody ${ }^{3}$, Guillaume Touya ${ }^{1}$, Tobias Kellenberger ${ }^{4}$, Demetris Demetriou $^{5}$

${ }^{1}$ IGN France, French Mapping Institute, COGIT Laboratory, 4 Avenue Pasteur, 94160 Saint-Mandé, France, ana-maria.raimond@ign.fr, guillaume.touya@ign.fr

${ }^{2}$ Nottingham Geospatial Institute, University of Nottingham, Nottingham, NG7 2TU, glen.hart.home@gmail.com

${ }^{3}$ School of Geography, University of Nottingham, Nottingham, NG7 2RD, UK, giles.foody@nottingham.ac.uk

${ }^{4}$ Federal Office of Topography swisstopo, Seftigenstrasse 264, 3084 Wabern, Switzerland, tobias.kellenberger@swisstopo.ch

${ }^{5}$ Public Works Department, Strovolos Avenue 165, 2048, Nicosia, Cyprus, demdeme@cytanet.com.cy

* Corresponding author: ana-maria.raimond@ign.fr

Short title: VGI and the National Mapping Agencies

Key words: neogeography, Volunteered Geographic Information (VGI), crowd sourcing, map production and updating. 


\begin{abstract}
.
The perspective of European National Mapping Agencies (NMA) on the role of citizen sensing in map production was explored. The NMAs varied greatly in their engagement with the community generating volunteered geographic information (VGI) and in their future plans. From an assessment of NMA standard practices, it was evident that much VGI was acquired with a positional accuracy that, while less than that typically acquired by NMAs, actually exceeded the requirements of the nominal data capture scale used by most NMAs. Opportunities for VGI use in map revision and updating were evident, especially for agencies that use a continuous rather than cyclical updating policy. Some NMAs had also developed systems to engage with citizen sensors and examples are discussed. Only rarely was VGI used to collect data on features beyond the standard set used by the NMAs. The potential role of citizen sensing and so its current scale of use by NMAs is limited by a series of concerns, notably relating to issues of data quality, the nature and motivation of the contributors, legal issues, the sustainability of data source, and employment fears of NMA staff. Possible priorities for future research and development are identified to help ensure that the potential of VGI in mapping is realised.
\end{abstract}




\section{$\underline{\text { 1. Introduction }}$}

Mapping practices and policies have evolved considerably over recent decades. Advances in geoinformation technologies have changed the way information is collected, analysed, stored and distributed. Moreover, the development of inexpensive location-aware devices and rise of Web 2.0 initiatives has seen considerable growth in citizen sensing, notably linked to the acquisition of volunteered geographic information (VGI) (Goodchild, 2007) in mapping. This type of activity is sometimes described with different terms, including crowdsourcing and neogeography (Turner, 2006) and although the distinctions between them can be important the focus on this paper is simply on citizen derived data. Together with a strong drive for openness this growth in citizen sensing has revolutionised aspects of mapping, notably in the development of projects such as OpenStreetMap (OpenStreetMap, 2014) and Wikimapia (Wikimapia, 2014).

With the adoption of Open Data Policy, many government data sets are now freely available to the public. The latter includes data from some European National Mapping Agencies (NMAs). For example the NMAs of Finland, The Netherlands, Germany, Great Britain and France have released at least a part of their data for free access. In most cases these data were integrated in OpenStreetMap (OSM). This has resulted in enhancements to the OSM data set but, critically, may have benefits for the NMAs. For example, Begin (2012) describes how the Canadian NMA released data to OSM and as a consequence data updates could be received from OSM contributors instead of NMA surveyors. The potential role of citizen sensing in the work of bodies such as the NMAs has been identified (Mooney and Morley, 2014; Haklay et al., 2014) but has not focused the actual and potential use of citizen sensor data in the mapping practices of official government agencies.

The vast potential of citizen sensing in mapping (Elwood, 2008) is, however, limited by concerns especially in relation to data quality (Haklay, 2010; Goodchild and Li, 2012) and trustworthiness of the data sets generated as compared to that from authoritative bodies such as the NMAs. However, 
authoritative bodies often struggle to acquire data at appropriate spatial and temporal dimensions and could potentially benefit from data provided by citizen sensors (Heipke, 2010). This article explores the current and potential role of citizen sensing in the work of authoritative European regional and national mapping agencies drawing on the results of a survey conducted from December 2013 to February 2014 and two workshops organised by the French Mapping Agency (IGN France) in March 2014 and swisstopo in February 2015. The work was conducted as part of COST Action TD1202 'Mapping and the Citizen Sensor' (Foody et al., 2014). In particular, Section 2 explores the mapping practices followed by NMAs in relation to VGI and critical data issues. Afterwards, Section 3 focuses on existing and potential future use of VGI by NMAs including specific examples and discussion on key issues. Finally, concluding remarks and future research directions are outlined in Section 4.

As the paper is constructed from an analysis of the outputs of a survey and two workshops involving members of NMAs it is not therefore a comprehensive review of VGI involvement with NMAs. As a consequence it will reflect an NMA perspective and be naturally light in areas such as motivation of VGI contributors. Such areas are likely to be explored in more detail as the COST Action proceeds.

\section{$\underline{\text { 2. The survey about mapping practices and use of VGI in NMAs }}$}

A total of 41 different organisations across Europe and Greenland who are members of EuroSDR and/or EuroGeographics were invited to take part in a survey to illustrate their mapping practices and use, actual and potential, of VGI. The organisations included often had a wide range of responsibilities and so here the focus was constrained to core issues of topographic and topologic (network) mapping that were common to all except one NMA.

The survey was web based using the Survey Monkey service as the method of delivery. It sought to obtain summary information organised in three sections: (i) the organisation's role; (ii) its survey specifications, maintenance regimes and validation/verification activity; and (iii) its current and proposed 
future engagement with VGI including quality control. In total 39 organisations responded to the invitation but only the data from 23 were complete and useable. The discussion below is based on the responses from these 23 organisations which arose from 19 countries (Table 1). Note in some cases, such as for Germany, there were responses from both national and regional agencies. Additionally, for the UK, participating organisations for Great Britain and Northern Ireland were treated as national rather than regional. Regarding the responsibilities of these organizations, the great majority focused on topographic surveying but other functions were also noted (Figure 1). The results of the survey informed two followon workshops that involved 11 of the organisations and which focused on their specific engagement and concerns with VGI. Three NMAs that had not participated in the survey (Cyprus, Netherlands and Romania) joined the workshops.

\subsection{Data capture and accuracy}

The nominal capture scale relates to the largest cartographic scale at which the mapping will be published and is important as it has been used by mapping agencies to determine the field survey accuracies required. In the context of using VGI, a key concern is that volunteers typically digitize information from aerial sensor imagery with a positional error that is often $>3 \mathrm{~m}$ (Barrette et al., 2000) or use uncorrected GNSS systems with positional accuracies that typically lie in the range 5-15 m (Unger et al., 2013).

The survey showed that the mapping agencies differed greatly in terms of their capture scale (Figure 2) and in the positional quality required in data collection (Figure 3). In particular, it was notable that most agencies captured data for mapping at scales of 1:10,000 or smaller and were acquiring the data for this mapping at a level of positional accuracy that was far greater than required to meet the needs of mapping at the nominal capture scale. More critically, for most NMAs volunteers could provide data with sufficient positional accuracy to meet NMA needs, even taking into account any confusion in reporting by the NMAs between accuracy and precision. Figure 4 shows a scatterplot of the nominal capture scale and survey accuracy for the NMAs together with an estimate for OSM. This latter estimate was inferred from 
studies on geometrical accuracy (Girres and Touya 2010, Haklay 2010), and on studies that tried to find the reference scale or level of detail for OSM (Reimer et al 2014, Touya and Reimer 2014).

\subsection{Data maintenance and updating}

Each mapping agency has a policy for the maintenance of data that involves systematic updating and map revision. Two maintenance policies are in common usage: cyclical or sweep revision, and continuous revision. Cyclical revision is the most traditional method and involves systematically updating areas corresponding to map sheets or tiles on a regular basis. Continuous revision consists of revising the map in order to capture changes of the whole area but with updates prioritised by the rate of change. Hybrid approaches also exist. For example, a policy based on continuous revision may also employ cyclical revision to acquire information and changes missed due to failings in change intelligence.

The survey shows that cyclical policies were more widely adopted than continuous policies. Specifically, 11 mapping agencies adopted a cyclical policy, 6 a continuous policy and 2 used both cyclical and continuous updating, although their primary revision policy was continuous. Unexpectedly, the survey showed that 4 of the organisations had not yet established policies, reflecting that they are relatively new. In the context of using VGI it is anticipated that volunteers might be particularly able to contribute information on change that is most suited to continuous revision. Volunteers might for example highlight areas that a mapping agency might wish to send professional survey staff to visit or submit new data that could be integrated into existing databases. It would still be possible for volunteers to contribute to cyclical revision but this might be best achieved in a highly steered activity with, for example, volunteers encouraged to focus on particular areas at a particular time. Continuous revision is only possible because of advances in the way that mapping data is held with databases and no longer managed as discrete map tiles. As more agencies develop this capability it is strongly suggested that they also adopt continuous revision as this is not only likely to lead to more up-to-date mapping, but also facilitate the use of VGI. 


\subsection{Provenance of meta-data and verification}

The registration of metadata is regarded as a good practice since it aids the evaluation of internal and external (fitness for use) quality (Dassonville et al., 2002; Devillers and Jeansoulin, 2005). Here, the concern is with the provenance of meta-data (i.e. recording how the data was obtained). The survey showed that all except one of the agencies recorded this information. Seventeen of the NMAs also acquired data and associated meta-data from authoritative professional sources (e.g. emergency services) and most of them, 15 in total, verified this information. On one hand the verification practice reflects the priority of the agencies to produce high quality, homogeneous and consistent data, and on the other hack the lack of methods allowing automatic verification and integration of new features. In the context of VGI this is important as it indicates that in some circumstances the costs of verifying VGI data may make it uneconomic unless more automated means can be found or consistent high quality demonstrated.

\section{Existing and potential future use of VGI}

VGI is not an entirely new issue for mapping agencies. The United States Geological Survey (USGS) seems to be the first national mapping organisation that allowed citizens to contribute information, starting with the Earth Science Corp, renamed later in National Map Corps, in 1991 (Bearden, 2007). Such pioneering efforts were limited by the available technology of the time but the vast technological advances made in recent years have reignited interest in VGI. In practice, all mapping agencies have traditionally used a kind of VGI by responding to reports of mapping errors and inconsistencies reported to them by members of the public. However, it is important to differentiate between this ad hoc process where the mapping agency is essentially a passive participant and processes in which the agencies actively engage with VGI, either to organise their own volunteer contributors, or through extracting information from existing VGI resources. The survey and following workshops sought to reveal the level of proactive engagement with VGI. 
The survey and workshops indicated that twelve out of twenty three agencies reported that they use VGI for: change detection, report alerts, collect new content, vernacular place names and photo interpretation. Figure 5 provides an overviewed of the use of VGI in the NMAs. Most of them have organised their own VGI collection processes whilst three agencies (Germany, Greece, Serbia) harvested and use data collected by OSM or GeoNames (GeoNames, 2014). In most cases the information gathered was on traditional features included in standard topographic maps. This is evident in the information provided by 7 mapping agencies that indicated the nature of the VGI used in detail (Figure 6). One near universal feature was that each agency that actively engaged with VGI checked the information received using a variety of sources of information including that acquired by their own survey staff directed to relevant sites. These area often time consuming processes and a need for more automated methods for the assessment of the quality of data received was identified. Overall, it was apparent that the mapping agencies were significantly engaged with VGI and that several organisations that do not currently exploit VGI plan to get involved in the near future. It is also apparent that in most cases current involvement is limited to change detection and error correction. Only two agencies use VGI as a primary data source or to collect data they would not otherwise collect. This situation suggests that mapping agencies do not currently fully exploit the new opportunities offered by VGI perhaps because of various concerns, some of which are discussed further below.

Nine NMAs have plans to either start collecting VGI (six agencies) or to further expand what they currently collect (three agencies). Those that did not have firm plans had a range of concerns that included worries about: infringement of copyright of data when using third-party VGI such as OSM, data quality, and data reliability. The remainder of this section focuses on some specific examples issued from workshops of how NMAs have engaged with VGI and their concerns with the use of VGI. 


\subsection{Examples of VGI use}

While open source tools are available such as OSM tools, it was evident that most of the mapping agencies surveyed had developed their own tools to collect data from the crowd or public partners. It should be noted that the maturity of tools varied from those developed for research projects to wellproven tools used fully operationally. This section gives an overview of some of the tools that have been developed and examples of the use of VGI in relation to the topics defined in Figure 5.

\subsubsection{Report Alerts}

IGN France developed a report alert system called Ripart, which has been in service since 2008 (Viglino 2009). It is a community-sourcing system where professional partners, such as the fire service, propose updates to IGN data by completing a form and providing location information using GPS tracks, photographs or drawings on a map. Ripart's reporting process enables the user to Ripart provides overlapping sketches of the proposed changes on an inert base map. Thus, the contributing partners do not have the ability to act directly on features belonging to the authoritative IGN database; to overcome this inconvenience a new version of the tool is being tested that allows partners access to a copy of topographic database (the last update: Day -1) and are able to directly add or modify geographic features.

The National Land Survey of Finland, which made its topographic database open to the public, has developed both a map interface (www.karttapaikka.fi) and a mobile application (www.karttaselain.fi) to collect feedback from citizens. Annually, it is estimated that some 500-700 reports are made using the map interface as well as 200-300 from the mobile application. The messages received are checked, replied to and most generate modification(s) in the agency's topographic database. Some updates are checked in the field or await to be verified and captured from scheduled aerial imaging.

In The Netherlands, Kadaster has developed a feedback system, Topographical Key Register (BRT) to collect feedback from map users. The system is deployed on tablets, smartphones and web platforms and 
is based on ArcGIS solutions. The data collected are validated after quality analysis and integrated in the database by surveyors from Kadaster. The agency of Switzerland, swisstopo, has a similar system in operation, which is integrated in the Web infrastructure of the Federal Spatial Data Infrastructure (FSDI). The so called revision client allows feedback from citizens from all standard platforms. The feedback from the citizens is validated and directly used in the map update process by the operators.

IGN Spain developed a report tool based on the National Geographic Information System (SIGNA) Geoportal. An online earthquake survey has also been developed that allows citizens to report earthquakes having at least 2.5 Richter scale magnitude or just felt by the population.

The Ordnance Survey of Great Britain has traditionally taken error and change reports from citizens via landline telephone calls and letters. A web based tool has been successfully trialed with public sector customers for reporting errors and omissions in a range of Ordnance Survey products. The TELL OS tool based on a five step process (i.e. select product, find location, submit data, contribution acknowledged, data stored) has a good use levels with almost 1500 reports per year.

\subsubsection{Change Detection}

Change detection is an important activity for most mapping agencies and can benefit from VGI. In The Netherlands Kadaster undertook a pilot test for change detection relating to roads and buildings in its 1:10k dataset (TOP10NL) from external sources (e.g. local administration datasets and OSM). This found that changes could be detected much more quickly than with the methods used conventionally at Kadaster.

At IGN France, change detection is made by land surveyors that analyse a range of alert types and contact

local administrators. It estimates that $75 \%$ of working time was dedicated to change detection, leaving only $25 \%$ for field work. It plans to develop a system to automatically infer change from the sources used 
by the surveyors, and from additional sources found on the web, including VGI from OSM, GPS tracks from hiking websites or Wikipedia. There are a range of concerns about the validation and integration of the data into the main database and tools to aid quality assessment and conflict management are being explored.

\subsubsection{Vernacular Place Names}

Citizens frequently use vernacular rather than official place names. Given that a vernacular place name may be in common usage but also different to the official name, there is a need to capture both. The OS undertook research with the UK Maritime and Coastguard Agency to improve the ability of the Coastguard to use vernacular place names to locate people in emergency situations. Preliminary results show that only $1 \%$ of names acquired in the study were not in current use and more critically that $95 \%$ could be accurately located.

The Swedish NMA, cadastral and land registration authority, proposed a smartphone application, named "Platsnamna", to collect vernacular place names which was tested in urban areas, being supported by the professionals and the public. Satisfactory results were obtained, new place names being suggested.

\subsubsection{New Data Collection}

VGI provides potential to capture new content, data on features not previously collected by the mapping agencies as not within their mission priorities or excluded for political or economic reasons. The Federal Agency for Cartography and Geodesy of Germany uses VGI to collect new content, features or attributes, such as buildings, structures (e.g. bridges, pylons, silos, dams), roads, tracks and paths, hydrographic features (e.g. rivers, lakes, canals), names, points of interest (e.g. tourist attractions, cash machines). New data are collected via secondary sources such as OSM. The NLS of Finland also found that cadastral boundary information could be acquired from owners with a high level of precision, typically within 0.5 $4.0 \mathrm{~m}$ of reality. 
In spring 2015 IGN France launched a crowdsourcing application dedicated to outdoor activities ${ }^{1}$. The application targets both individuals with interests such as trekking, and community sourcing with outdoor activity companies being able to reserve data for exclusive use, e.g. a rafting company provides a smartphone application to its customers, with its own data conflated with the IGN data.

\subsection{Concerns with VGI}

It was notable that in some cases VGI may be of sufficient accuracy for NMA needs and may even sometimes be more accurate in terms of clarity and level of detail compared to the available professional geographic information (Parker et al., 2012). On the other hand, the use of VGI by mapping organisations involves risks that raise a number of critical issues that need to be resolved. Five major barriers to the use of VGI were identified during the workshops: data quality and validation, legal issues, nature and motivation of the crowd, sustainability, and employment fears.

\subsubsection{Data Quality and Validation}

The quality of data arising from citizen sensors was viewed by all of the agencies as a concern, reflecting in part the importance that the mapping agencies place on maintaining their reputation for high quality products. Some research suggests that the quality of VGI increases with the number of contributors (Haklay et al., 2010; Girres and Touya, 2010; Foody et al., 2015) and hence if mapping agencies want to maintain high quality standards they may need to involve many contributors.

Most academic research on data quality has focused on the issues of positional accuracy and completeness (Haklay, 2010, Girres and Touya, 2010, Koukoletsos et al., 2012), semantic accuracy (Fan et al., 2014) or currency (Jokar Arsanjani et al., 2013), especially with regard to OSM. However, as noted above, the positional accuracy of much VGI may actually be sufficient for the needs of mapping agencies.

${ }^{1}$ http://espaceloisirs.ign.fr/ 
Other aspects of mapping practice have attracted little research. There has been little research on the perceived lack of homogeneity of VGI (e.g. a lack of overall consistency in terms of what is mapped, how detailed the mapping is, and how it is then classified) and its impacts but some recent research on OSM showed that the scale or level of detail of individual features can be inferred. For example, in some VGI data sets the information on buildings in some places may be very detailed because it has been imported from available cadastral data, but less detailed elsewhere as, perhaps, captured from satellite imagery. It has been shown that key details of individual features may be inferred from their geometry, semantics or metadata (Touya and Brando, 2013; Reimer et al., 2014) allowing the variation to be quantified. This then offers the potential to allow it to be integrated into a NMAs mapping processes that are made for homogeneous data as the variability of detail can be clearly differentiated.

Some applications require the use of authoritative data such as for cadastral tasks, planning and design at various levels. On the other hand, VGI could be enough for applications such as preliminary planning (e.g. national, regional and urban), car navigation, transport management systems and visual analysis.

\subsubsection{Legal Issues}

Integrating VGI data in authoritative mapping agency databases raises also legal concerns, including those connected with intellectual property rights, privacy, and legal liability (Scassa, 2013). VGI hosts generally protect their intellectual property interests in their websites by copyright laws. Since authoritative databases also have copyright laws, although the scope of protection may vary significantly, it becomes unclear who owns and is responsible for the data if different sources of data are integrated or used. Research on copyright and public domains should help the mapping agencies address some of the important legal concerns that they have (Dulong de Rosnay and De Martin, 2012; Scassa, 2012). As an example of licencing issues, IGN France and OpenStreetMap France are collaborating on a joint project to build an open dataset for the crowdsourced collection of unified addresses. One of the main technical 
problems is the incompatibility between OSM's ODBL licence and the French administration's open licence, which has forced the duplication of data on several servers.

Legal liability is an important issue for national mapping agencies since errors in the data due to the integration of imperfect VGI data could cause physical injuries or even the loss of life. In such cases, the issue of who is liable for the incorrect decision making and consequential damages arises. This issue is linked closely to the concerns with data quality noted above. Scassa (2012) argues that legal liability of VGI would encourage contributors to produce quality data but discourage non-confident contributors. The creation of associations of volunteers can also help volunteers to avoid legal liability risks (Shanley, 2012). In the case of authoritative organisations that integrate VGI, Rak et al. (2012) study the questions 'who is liable and when' under Canadian law and provide guidelines for risk management techniques related to VGI. When mapping agencies are responsible for cadastre, the authoritativeness of VGI could be decided by court decisions (Scassa, 2012) which is a clear barrier for agencies until jurisprudences clarify the case.

Furthermore, it may not be obvious that the source of VGI is legitimate. For example digitising from other mapping or imagery for which permissions had not been obtained would be illegitimate. Whilst this may occur in only a minority of cases NMAs will need to develop ways to protect themselves against such incidents.

Making general statements is further complicated by the variation in law between nations. For instance, the French outdoor activities crowdsourcing application being launched in spring 2015 (see above) has specific terms of use stating that each contributor has copyright on his/her contributions and is responsible for their correctness.

\subsubsection{Nature of the Crowd and Motivation}


The nature of the crowd and the credibility of volunteers is also a key point for NMAs. Although potentially anyone can contribute VGI, the community of volunteers is often very unrepresentative of the population. For example, with OSM, the typical contributor is a male, well-educated and technologysavvy (Schmidt and Klettner, 2013). Additionally, it seems that males may mostly contribute through private interest while females do so in the context of their work (Schmidt and Klettner, 2013). OSM contributors also vary greatly in terms of activity (Neis and Zipf, 2012). Coleman et al. (2009) recognise five overlapping categories of VGI contributors reflecting the wide spectrum of motivations: 'neophyte', 'interested amateur', 'expert amateur', 'expert professional' and 'expert authority'.

Developing means to measure the credibility of contributors and/or their contributions may help mapping agencies make use of VGI. Flanagin and Metzner (2008) focus on the measurement of credibility in web 2.0 applications (i.e. forums or social networks). Skarlatidou et al. (2011) focus on the assessment of trust through reputation and expertise. Bishr and Janowicz (2010) also apply social network reputation measures to VGI with, for instance, a contributor's credibility assessed by votes from other contributors. Others propose methods to rank an OSM contributor according to the time spent on OSM, or the use of its local knowledge (van Exel et al., 2010; Napolitano and Mooney, 2012); and others such as Kessler and de Groot (2013) compute credibility measures on contributions rather than contributors showing some correlation between quality and credibility. Foody et al. (2013) asses the accuracy of VGI contributors from the data that they provide via a latent class analysis.

A key attraction of VGI is that the contributor often has in-depth local knowledge (Goodchild, 2007). The data provided may not be homogenous but with some themes such as roads can be of better quality than authoritative data sets, certainly in terms of completeness and required positional accuracy, at least for urban areas (Haklay, 2010). The desire to exploit this information and engage a large community has driven research on the motivation of the volunteers. People are motivated in a variety of ways. They may motivated be emotionally such as in relation to a natural disaster (Goodchild and Glennon, 2010) or when 
the action is in their best interest. Cadastral mapping is an example where contributors (generally owners) are motivated to map and update the cadastre helping to reduce costs and time as well as removing errors (Basiouka and Potsiou, 2012; Laarakker and de Vries, 2011). Maintaining the interest of contributors was seen as important and this benefited from the provision of feedback to contributors and the rapid update of the topographic database. There is a risk here that VGI contributors may possibly be motivated by building an alternative to authoritative data (a kind of libertarianism) and may not be attracted to NMAs VGI systems. More specifically, it is quite unlikely that capturing authoritative VGI will attract all OSM contributors, so the NMAs will have to motivate different contributors to build a community large enough to support their needs. This is an issue that should be studied in future work. Mapping agencies from Finland, France and Netherlands mentioned that people feel rewarded when they notice that their contribution is taken into account. For example, Netherlands' Kadaster has good experience in collecting VGI data by providing a prototype system comprising web, mobile phone and tablet applications; emails, tweets and interactive human computer interface are used to inform users who reported changes or errors.

\subsubsection{Sustainability}

Related to the motivation to contribute VGI, the mapping agencies were concerned about the sustainability of the volunteer community and its data flow. Mapping agencies have concerns over the stability and the long-term viability of VGI initiatives, founded on an untested belief that volunteers may be motivated notably for one-off capture. This is of course not a problem if a one-off contribution is what is required with further data capture the responsibility of the agency itself. The issues are, however, complex as citizen contributors may be motivated in different ways; some may be volunteers, others responding to small payment incentives and some may be open to direction. It is known that VGI can be effectively organised, for example, the mayor of a village in France (Brocas, Landes, approximately 800 inhabitants) organised a mapping party and invited OSM contributors through the website of the French community to produce open data (Larousserie, 2013). However, given the diverse nature of the VGI 
community, mapping agencies wish to know more about how to keep volunteers motivated and how to grow the volunteer community.

A variety of motivations may be observed, notably fun, fame or fortune (Coleman et al., 2009; Kaufmann et al., 2011; Kazai et al., 2013). Games can be motivating for some contributors. For example, gaps in OSM coverage have been filled through the use of a game to motivate OSM contributors (Antoniou and Schlieder, 2014). Similarly, GeoCaching is a most successful location-based game, with millions of caches and users. Understanding the motivations of the geocachers would help mapping agencies to propose attractive game-orientated VGI projects (O'Hara, 2008; Neustaedter et al., 2013). It may also be possible to build on the success of social media such as FourSquare in which people locate themselves in places that they recommend such as shops or restaurants (Lindqvist et al., 2011). Indeed, a similar idea was supported by IGN Spain in which a location based game named Town Conquer, to validate toponyms, was developed (Castellote et al., 2014). In this, players fill in the names of places in order to win points and conquer the territory starting with provinces, regions up to the country. Other systems may be used to involve people in games to collect valuable VGI. For example, competitions and games with different levels of difficulty to capture data on croplands in order to improve land cover data and which offer contributors incentives such as small prizes have been run in association with the Geo-Wiki system (See et al., 2014). Given the previously noted importance of reputation, mapping agencies are however concerned about managing the potential conflicts linked to being a 'serious' agency with the fun of crowdsourcing.

\subsubsection{Employment Concerns}

A concern noted by the mapping agencies was the fear their staff may have in relation to their job security. The staff concerns perhaps reflect an understandable view point in which VGI is seen as a potential replacement for authoritatively collected data. As such mapping agencies may need to develop new communication policies to inform staff of the role of VGI and how it can facilitate the work of the 
agency. Given the aforementioned concerns with VGI it is also evident that it cannot currently emulate the authoritative mapping of the professional mapping agencies. The continuing evolution of the mapping profession could, however, reflect the potential of VGI. For example, the role of the authoritative surveyor might adapt to one in which greater emphasis is given to activities such as the integration of complementary data from VGI sources or validating updates coming from citizen sensors. Critically, VGI should not be seen as a replacement for authoritative data or a threat to the professional mapping community but as a potentially useful resource to aid mapping by combining VGI with professionally acquired geographic information for the broader social benefit (Parker et al., 2012). However, some researchers highlight that VGI may be a threat for citizens. Renee Sieber advised that care was needed to avoid a kind of techno-libertarianism that would "control" contributors (Sieber, 2014), while others have compared crowdsourcing as microfascism (Gilge, 2014).

From the author's point of view, a better relationship between NMAs and the VGI community could be the key to success. This involves a win-to-win relationship where both NMAs and VGI communities' expectations are satisfied. Figure 7 summarises the most important expectations from the authors' point of view. For the VGI community one of the most important expectations is feedback. The NMAs should give immediate notification, show all contributions, validate and integrate them into the authoritative data immediately. To this purpose, one possibility is for the NMAs to make the citizen data available as a citizen layer that can be associated with the authoritative data layers, keeping the citizen and authoritative data separate but enabling both to be used together if desired. At the same time, NMAs expect from the VGI Community motivation, stability over time, no fakes, consistency with others layers proposed by the mapping agencies or uniformity (e.g. spatial and attribute completeness and homogeneity). To improve the relationships with the VGI community, the NMAs expect from the research community new methods, reliable processes for conflict resolution and data integration, new techniques and guidelines to break down the identified barriers. 


\section{Conclusions}

The survey and workshops that underpin this paper sought to better understand practices, experiences and needs of national mapping agencies concerning VGI, especially as a means to share information to and support a wider engagement with the VGI community. It was evident that most of the mapping agencies involved had some engagement with the VGI community and others have plans to develop this activity. Opportunities for the use of VGI were apparent, especially given the positional accuracy of some VGI data sets and the potential for use with respect to continuous revision. Indeed, in agencies using citizen sensor data, VGI was often used for change detection and the identification of errors. Only very rarely, however, was it integrated directly into the authoritative databases. The activities of communities such as those linked to OSM has not changed the way mapping agencies produce data and the majority did not view OSM data as currently being highly useful. The reasons for this may be quite complex. Most of the NMAs have some concerns regarding the quality and the heterogeneity of VGI. Moreover, legal aspects uncertainties and the manner in which much data is collected as typified by aspects such as the applied classifications are reasons behind this situation.

Most of the current or planned activity with VGI was conservative: the mapping agencies were trying to fit VGI activity around existing capture specification. The majority of agencies were currently against some activities that could encourage greater use of VGI such as incorporating and clearly identifying VGI data as such and allowing less strict validation. Thus, the agencies did not wish to provide a 'citizen layer' where citizen updates are publicly available but not authoritatively checked. Indeed, for most NMAs, the integration of VGI data directly in authoritative databases was not viable. The inexpensive nature of VGI was not an issue to the NMAs. It was evident that for countries where the data coverage was incomplete VGI was not being used, nor planned for use, to complete it. This happens because NMAs are state entities that are officially responsible to provide accurate and reliable spatial data infrastructure (SDI) to all potential users hence they are wary of potentially flawed VGI provided by the public. 
Although VGI offers the mapping agencies potentially useful data, a series of obstacles to its use were evident, notably relating to issues such as data quality, legal issues and sustainability. Some research on these has been undertaken but further research needs to be done to enhance the tie between mapping agencies and VGI community. Much of the research on issues of data quality has to-date focused on issues such as positional accuracy and to a lesser extent completeness and classification accuracy; much more research is needed in issues such as updated-ness, maintenance or currency and legal issues. Priorities need to be established to help define strategies that can make use of VGI. Many of the mapping agencies are developing tools to collect data from the public partners or the crowd and hence activity to identify good/best practices will be helpful. How can mapping agencies create dedicated communities that persist over time? Should there be active collaboration with groups such as those contributing to OSM? How will mapping agencies use VGI while respecting INSPIRE rules? The INSPIRE directive aims to create an European Spatial Data Infrastructure. This will enable the sharing of spatial infrastructure provided by public sector authorities to all citizens so it should considerable enhance public access to spatial infrastructure across Europe. INSPIRE should enhance VGI by providing several free data; on the other hand VGI will continue to provide complementary and updated information (where NMAs cannot afford to do this) not available by INSPIRE. Some VGI can be included in the near term within INSPIRE if there are adequate validation mechanisms for improving or just reporting its quality.

Issues such as legal issues, nature and motivation of the crowd and sustainability were not only identified as a barrier but also as a goal of any NMAs to reduce these barriers by responding to questions such as: How to keep contributors and grow the community of contributors? How to motivate them? How to deal with legal issues and licenses? There was great uncertainty over legal issues connected with the use of VGI. Developing from the survey and workshop, it is intended to further study the current practices of 
national mapping agencies and compare them between national and regional bodies (e.g. Germany, Italy) as well as explore how others organisations such as Microsoft, Google or USGS manage the legal issues.

While the activity of the various VGI communities has not yet substantially changed the way the NMAs produce data, change in the future could be anticipated and the role of VGI community and NMAs could be reviewed. Nevertheless, it is difficult to identify a clear direction towards which NMAs in Europe are headed in regards to VGI since most of them are public bodies and they are often affected by political decisions. Moreover, the development of VGI is heterogeneous across Europe, as it is across the world, which leads to many different positions of NMAs regarding VGI. To the best of the authors' knowledge, the economic models of NMAs are changing and need to be adapted to the new reality in which VGI is abundant by, for example, proposing paid services based on geographic data rather than just data or 'win to win services'. From the authors' point of view, even if some barriers are broken down, VGI cannot completely replace authority data; the authors, without engaging the institution to which they belongs, do however believe that NMAs will exploit the potential of VGI in order to reduce their production costs and improve currency by defining new workflows for VGI integration and quality assurance on the one hand and building trust and cooperation with VGI communities and citizens on the other hand.

\section{Acknowledgements}

This study was supported by the COST Action TD1202 Mapping and the Citizen Sensor funded by the European Union Seventh Framework Programme and European Science Foundation. The authors would like to thank the COST Action TD1202, the national mapping agencies which responded to the survey and the representativesldelegates of NMA who participated to the meeting: Peter Penev, Andreas Hadjiraftis, Marie Laasko, Loic Gondol, Bianka Fohgrub, Magdalena Grus, Jusper Hogerwerf, Oana Popescu, Ana Velasco-Tirado, Pär Hedén and Chris Philips. Finally, we are grateful to the 4 referees for their helpful comments on the original manuscript. 


\section{References}

Antoniou V and C Schlieder 2014 Participation patterns, VGI and gamification. In Proceeding of: 17th AGILE Conference on Geographic Information Science - Geogames and Geoplay Workshop, Castellon, Spain

Barrette J, August P, and Golet F 2000 Accuracy assessment of wetland boundary delineation using aerial photography and digital orthophotography. Photogrammetric Engineering and Remote Sensing 66: 409416

Basiouka S and Potsiou C 2012 VGI in cadastre A Greek experiment to investigate the potential of crowd soursing techniques in Cadastral Mapping. Survey Review, 44: 153-161

Begin D 2014 Towards integrating VGI and national mapping agency operations - a Canadian case study. In Workshop on Role of Volunteered Geographic Information in Advancing Science: Quality and Credibility. Columbus $(\mathrm{OH})$, USA

Bishr M and Janowicz K 2010 Can we trust information? - the case of volunteered geographic information. In Towards Digital Earth: Search, Discover and Share Geospatial Data, Workshop at Future Internet Symposium, Berlin, Germany

Bearden M J 2007 The National Map Corps. The USGS's Volunteer Geographic Information Program. In Workshop on Volunteered Geographic Information. University of California, Santa Barbara, USABrown M. Sharples S, Harding J, Parker C J, Bearman N, Maguire M, Forrest D, Haklay M and Jackson M, 2013. Usability if geographic information: Current challenges and future directions. Applied Ergonomics 44: $855-865$

Castellote J, Huerta J, Pescador J and Brown M 2014 Town conquer : a gamified application to collect geographical names. In J. Huerta (Ed.), Proceedings of the AGILE'2014 International Conference on Geographic Information Science, Castellón, Spain

Coleman D, Georgiadou Y, Labonte J 2009 Volunteered geographic information: The nature and motivation of producers. International Journal of Spatial Data Infrastructures Research, 4: 332-358 
Dassonville L, Vauglin F, Jakobsson A and Luzet C 2002 Quality management, data Quality and users, metadata for geographical information. In : Shi, W., Fisher, P.F. et Goodchild, M.F (éd.), Spatial Data Quality. Taylor \& Francis, p. 13

Devillers R.and Jeansoulin R 2005 Qualité de l'information géographique. Paris : Hermès et Lavoisier Dulong de Rosnay M and De Martin J C (Eds.) 2012 The Digital Public Domain. Cambridge, UK: Open Book Publishers

Elwood S 2008 Volunteered geographic information: future research directions motivated by critical, participatory, and feminist GIS. GeoJournal, 72: 173-183

Fan H, Zipf A, Fu Q and Neis P 2014 Quality Assessment for Building Footprints Data on OpenStreetMap. International Journal of Geographical Information Science 28(4): 700-719, doi: $10.1080 / 13658816.2013 .867495$

Flanagin A and Metzger M 2008 The credibility of volunteered geographic information. GeoJournal 72: 137-148

Foody G M, See L, Fritz S, Van der Velde M, Perger C, Schill C. and Boyd D S 2013 Assessing the accuracy of volunteered geographic information arising from multiple contributors to an internet based collaborative project. Transactions in GIS 17: 847-860

Foody, G., Fritz, S., See, L., Kerle, N., Hart, G. and Fonte, C., 2014. Enhancing the role of citizen sensors in mapping: COST Action TD1202, In: Huerta, Schade, Granell (Eds): Connecting a Digital Europe through Location and Place. Proceedings of the AGILE'2014 International Conference on Geographic Information Science, Castellón, June, 3-6, 2014. ISBN: 978-90-816960-4-3

Foody, G. M., See, L., Fritz, S., van der Velde, M., Perger, C., Schill, C., Boyd, D. S. and Comber, A., 2015. Accurate attribute mapping from volunteered geographic information: issues of volunteer quantity and quality, The Cartographic Journal, (in press)

GeoNames 201. GeoNames Available at URL http://www.geonames.org/ 
Gilge C 2014 Citizen participation as microfascism: the darker side of creative austerity of neoliberalism, ACSP 54th Annual Conference, Philadelphia, PA, USA

Girres J.-F and Touya G 2010 Quality assessment of the french OpenStreetMap dataset. Transactions in GIS 14: 435-459

Goodchild M F 2007 Citizens as sensors: the world of volunteered geography. GeoJournal, 69: 211--221

Goodchild M F and Glennon . J 2010 Crowdsourcing geographic information for disaster response: a research frontier. International Journal of Digital Earth 3: 231-241

Goodchild M.F and Li L. 2012 Assuring the quality of volunteered geographic information. Spatial Statistics, 1: 110-120

Haklay M 2010 How good is volunteered geographical information? A comparative study of OpenStreetMap and ordnance survey datasets. Environment and Planning B: Planning and Design 37: $682-703$

Haklay M, Basiouka S, Antoniou V and Ather A 2010 How many volunteers does it take to map an area well? the validity of linus's law to volunteered geographic information. The Cartographic Journal 47: $315-322$

Haklay M, Antoniou V, Basiouka S, Soden R, and Mooney P 2014 Crowdsourced geographic information use in government, Report to GFDRR (World Bank). London

Heipke C 2010 Crowdsourcing geospatial data. ISPRS Journal of Photogrammetry and Remote Sensing, 65: $550-557$

Jokar A.J., Helbich M., Bakillah M., and Loos L. 2013 The emergence and evolution of OpenStreetMap: a cellular automata approach. International Journal of Digital Earth, 1-15

Kaufmann N, Schulze T and Veit D 2011 More than fun and money. Worker motivation in crowdsourcing - a study on Mechanical Turk, AMCIS. 2011, 11 pp

Kazai G, Kamps J and Milic-Frayling N 2013 An analysis of human factors and label accuracy in crowdsourcing relevance judgements Information Retrieval 16: 1-41 
Keßler C and de Groot R T 2013 Trust as a proxy measure for the quality of volunteered geographic information in the case of OpenStreetMap. In D. Vandenbroucke, B. Bucher, and J. Crompvoets (Eds.), Geographic Information Science at the Heart of Europe, pp. 21-37. Springer

Koukoletsos T, Haklay M and Ellul C 2012 Assessing data completeness of VGI through an automated matching procedure for linear data. Transactions in GIS 16: 477-498

Laarakker P and de Vries W T 2011 http://www.opencadastre.org: Exploring Potential Avenues and Concerns. Proceedings of the FIG Working Week 2011, Marrakech, Morocco

Larousserie D 2013 Un village landais reprend possession de ses données. Le Monde, 6th May 2013

Lindqvist J, Cranshaw J, Wiese J, Hong J and Zimmerman J 2011 I'm the mayor of my house: Examining why people use foursquare - a social-driven location sharing application. In Proceedings of the SIGCHI Conference on Human Factors in Computing Systems, CHI '11, New York, NY, USA, pp. 2409-2418. $\mathrm{ACM}$

Mooney P and Morley J 2014 Crowdsourcing in National Mapping. European Spatial Data Research 64: $147-166$

Napolitano M and Mooney P 2012 MVP OSM: A tool to identify areas of high quality contributor activity in OpenStreetMap. The Bulletin of the Society of Cartographers

Neis P and Zipf A 2012 Analyzing the contributor acitivity of a volunteered geographic information project - the case of OpenStreetMap. ISPRS International Journal of Geoinformation 1: 146-165

Neustaedter C, Tang A and Judge T K 2013 Creating scalable location-based games: Lessons from geocaching. Personal Ubiquitous Comput. 17: 335-349

O'Hara K 2008 Understanding geocaching practices and motivations. In Proceedings of the SIGCHI Conference on Human Factors in Computing Systems, CHI '08, New York, NY, USA, pp. 1177-1186.

OpenStreetMap, 2014. OpenStreetMap, Available at URL www.openstreetmap.org

Parker C. May A, Mitchell V 2012 Understanding design with VGI using an information relevance framework. Transactions in GIS 16: 545-560 
Rak A, Coleman D and Nichols S 2012 Legal liability concerns surrounding volunteered geographic information applicable to Canada. In A. Rajabifard and D. Coleman (Eds.), Spatially enabling government, industry and citizens, USA, pp. 125-143. GSDI Association Press

Reimer A, Kempf, C, Rylov M and Neis P 2014 Assigning scale equivalencies to OpenStreetMap polygons. In Proceedings of AutoCarto 2014, Pittsburgh, USA

See L, Sturn T, Perger C, Fritz S, McCallum I and Salk C 2014 Cropland capture: A gaming approach to improve global land cover. In J. Huerta, S. Schade, and C. Granell (Eds.), Connecting a Digital Europe through Location and Place. Proceedings of the AGILE'2014 International Conference on Geographic Information Science, Castellón, Spain. AGILE

Scassa T 2012 Problems with authority: the role of law as a barrier to authoritative VGI. In Workshop on Role of Volunteered Geographic Information in Advancing Science: Quality and Credibility, Columbus $(\mathrm{OH})$, USA

Scassa T, 2013 Legal issues with volunteered geographic information. The Canadian Geographer 57: 110

Sieber, R, 2014 The Science of Citizen Science, Volonteered Geographic Information and Public Participation GIS, Keynote speech at GIScience 2014, Austria

Shanley L 2012 Legal and policy challenges of volunteered geographic information in the united states. In Workshop on Role of Volunteered Geographic Information in Advancing Science: Quality and Credibility, Columbus (OH), USA

Skarlatidou A, Haklay M and Cheng T 2011 Trust in web GIS: the role of the trustee attributes in the design of trustworthy web GIS applications. International Journal of Geographical Information Science 25: $1913-1930$

Touya G and Brando C 2013 Detecting Level-of-Detail inconsistencies in volunteered geographic information data sets. Cartographica: The International Journal for Geographic Information and Geovisualization 48: 134-143 
Touya G and Reimer A 2014 Inferring the Scale of OpenStreetMap Features. In J.J. Arsanjani, A. Zipf, P Mooney and M. Helbich (Eds.), OpenStreetMap in GIScience: experiences, research, applications. Lecture Notes in Geoinformation and Cartography, Springer

Turner AF 2006 Introduction to neogeography, Sebastopol, CA: O'Reilly.

Unger D, Hung I, Zhang Y, Parker J, Kulhavy D and Coble D W 2013 Accuracy Assessment of Perimeter and Area Calculations Using Consumer-Grade GPS Units in Southern Forests. Southern Journal of Applied Forestry 37: 208-215

van Exel M, Dias E. and Fruijtier S 2010 The impact of crowdsourcing on spatial data quality indicators. In R. Purves and R. Weibel (Eds.), Extended Abstracts Volume, GIScience 2010, Zurich, Switzerland Viglino J-M 2009 Managing partners feedbacks through the geoweb. In Proceedings of First EuroSDR Workshop on Crowd Sourcing for Updating National Databases, Wabern, Switzerland. EuroSDR Wikimapia, 2014. Wikimapia, Available at URL http://old.wikimapia.org 


\begin{tabular}{|l|l|l|}
\hline Country & Organisation name & $\begin{array}{l}\text { Scope of the } \\
\text { Organisation }\end{array}$ \\
\hline Belgium & National Geographic Institut of Belgium & National \\
\hline Cyprus* & Lands and Surveys of Cyprus & National \\
\hline Finland & National Land Survey of Finland & National \\
\hline France & $\begin{array}{l}\text { National Institute for Geographic Information and } \\
\text { Forestry }\end{array}$ & National \\
\hline Germany & Federal Agency for Cartography and Geodesy & National \\
\hline Germany & $\begin{array}{l}\text { Bavarian Agency for Surveying and Geographical } \\
\text { Information }\end{array}$ & Regional \\
\hline Great Britain & Ordnance Survey of Great Britain & National \\
\hline Greece & Hellenic Military Geographical Service & National \\
\hline Greenland & Asiaq - Greenland Survey & National \\
\hline Iceland & National Land Survey of Iceland & National \\
\hline Ireland & Ordnance Survey Ireland & National \\
\hline Italy & Bruno Kessler Foundation & National \\
\hline Latvia & Latvian Geospatial Information Agency & National \\
\hline Lithuania & National Land Service & Regional \\
\hline Netherlands* & National Agency for Cadastre and Land Registration & National \\
\hline Northern Ireland & Land and Property Services, Northern Ireland & National \\
\hline Norway & Norwegian Mapping Authority & National \\
\hline Portugal & Direção-Geral do Território & National \\
\hline Romania* & National Agency for Cadastre and Land Registration & National \\
\hline Serbia & Republic Geodetic Authority & National \\
\hline Spain & National Geographic Institute of Spain & National \\
\hline Sweden & Mapping, cadastral and land registration authority & Regional \\
\hline Switzerland & Federal Office of Topography-Swisstopo & National \\
\hline & & \\
\hline
\end{tabular}

Table 1: European countries participating in the survey, plus Greenland (*NMAs participating only to the workshop) 


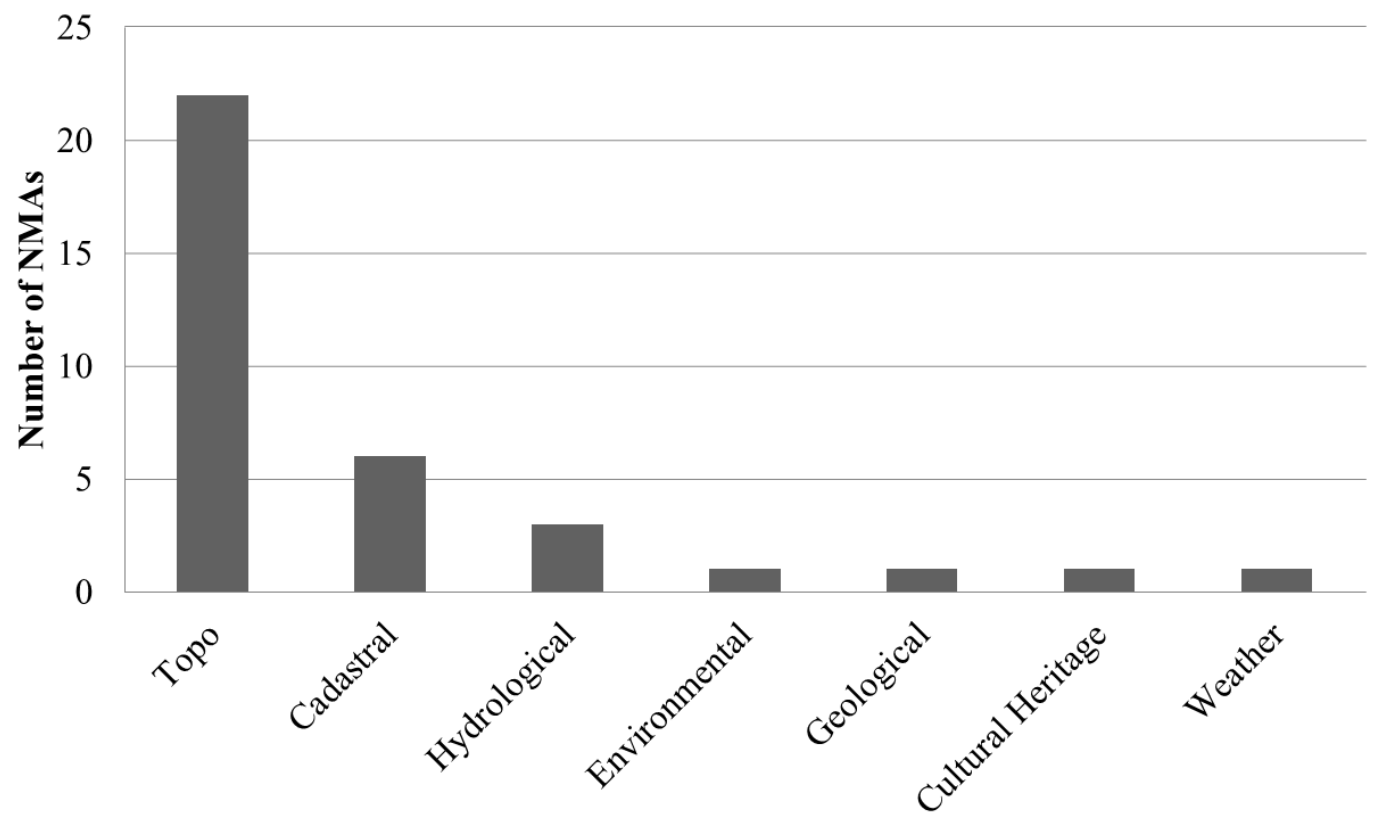

Figure 1. Organisational responsibilities by function 


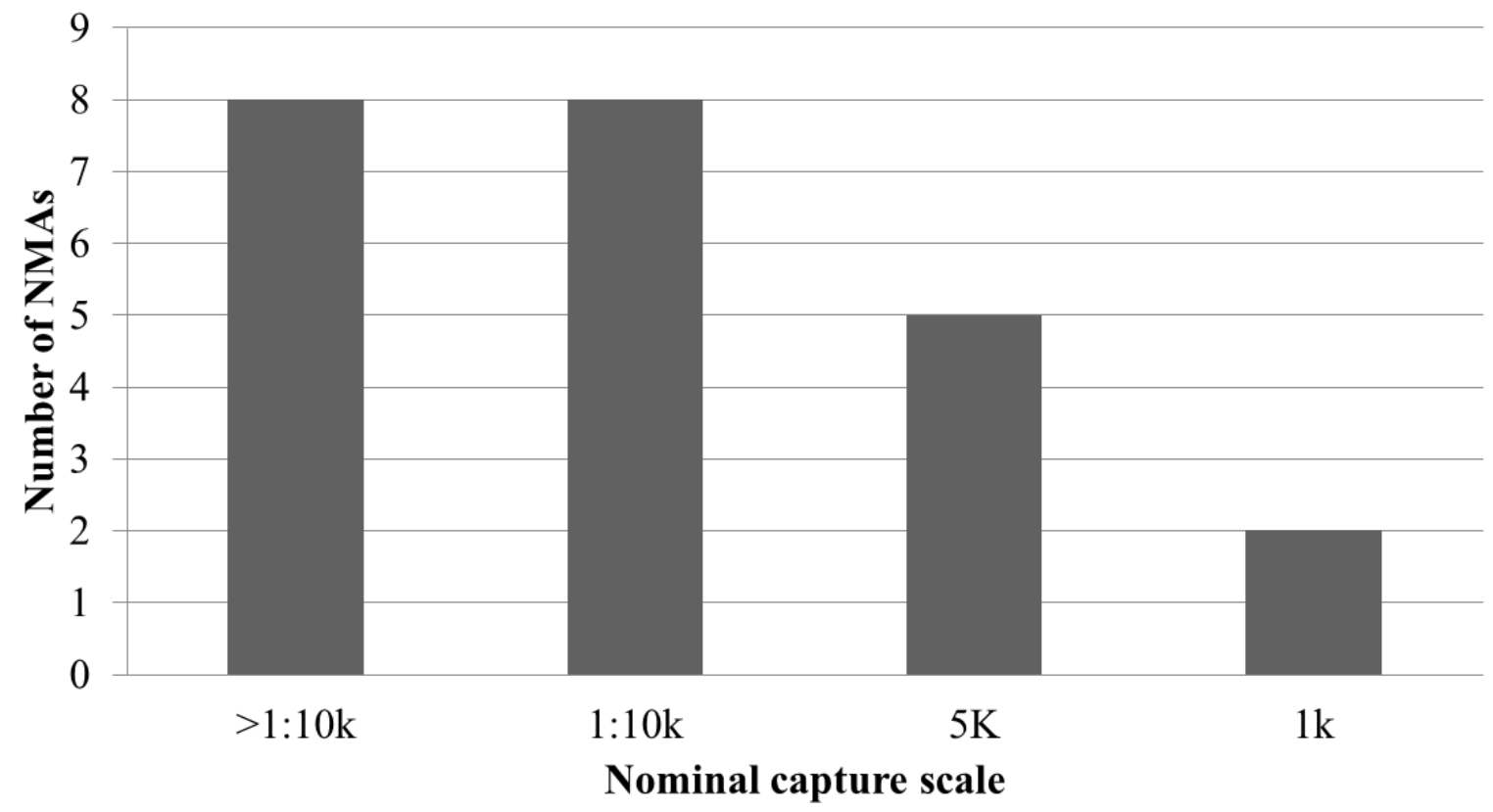

Figure 2. Nominal capture scale by mapping agencies 


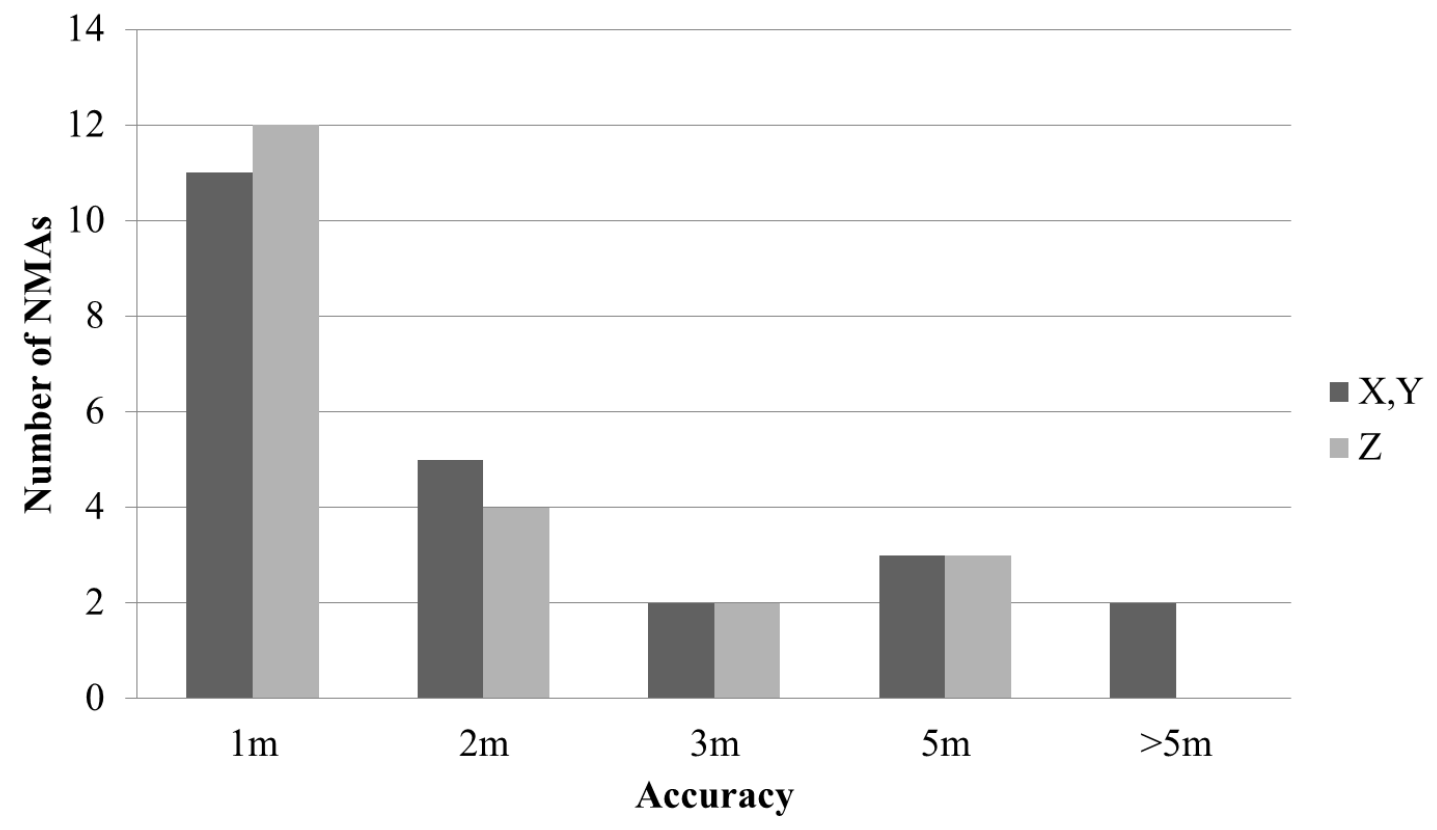

Figure 3. Survey accuracies by organisational count. 


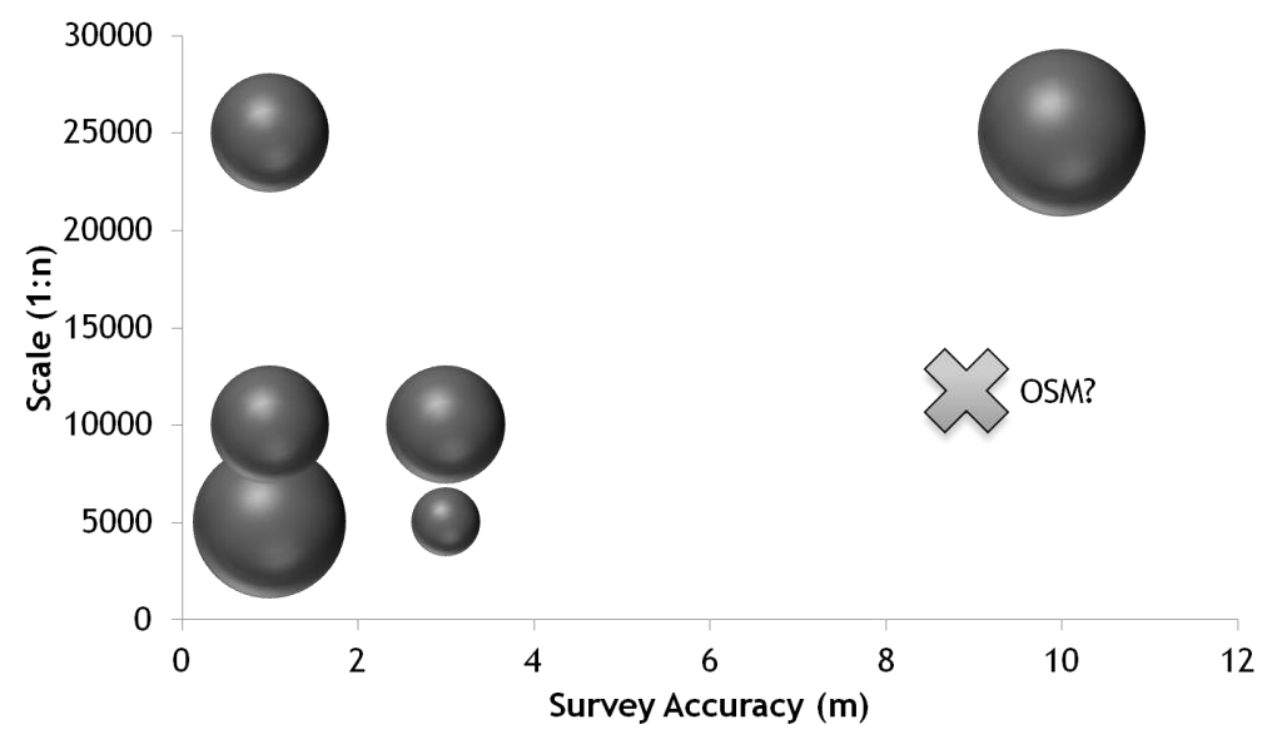

Figure 4. Survey accuracy versus nominal capture scale. Symbol size is proportional to the number of NMAs. 


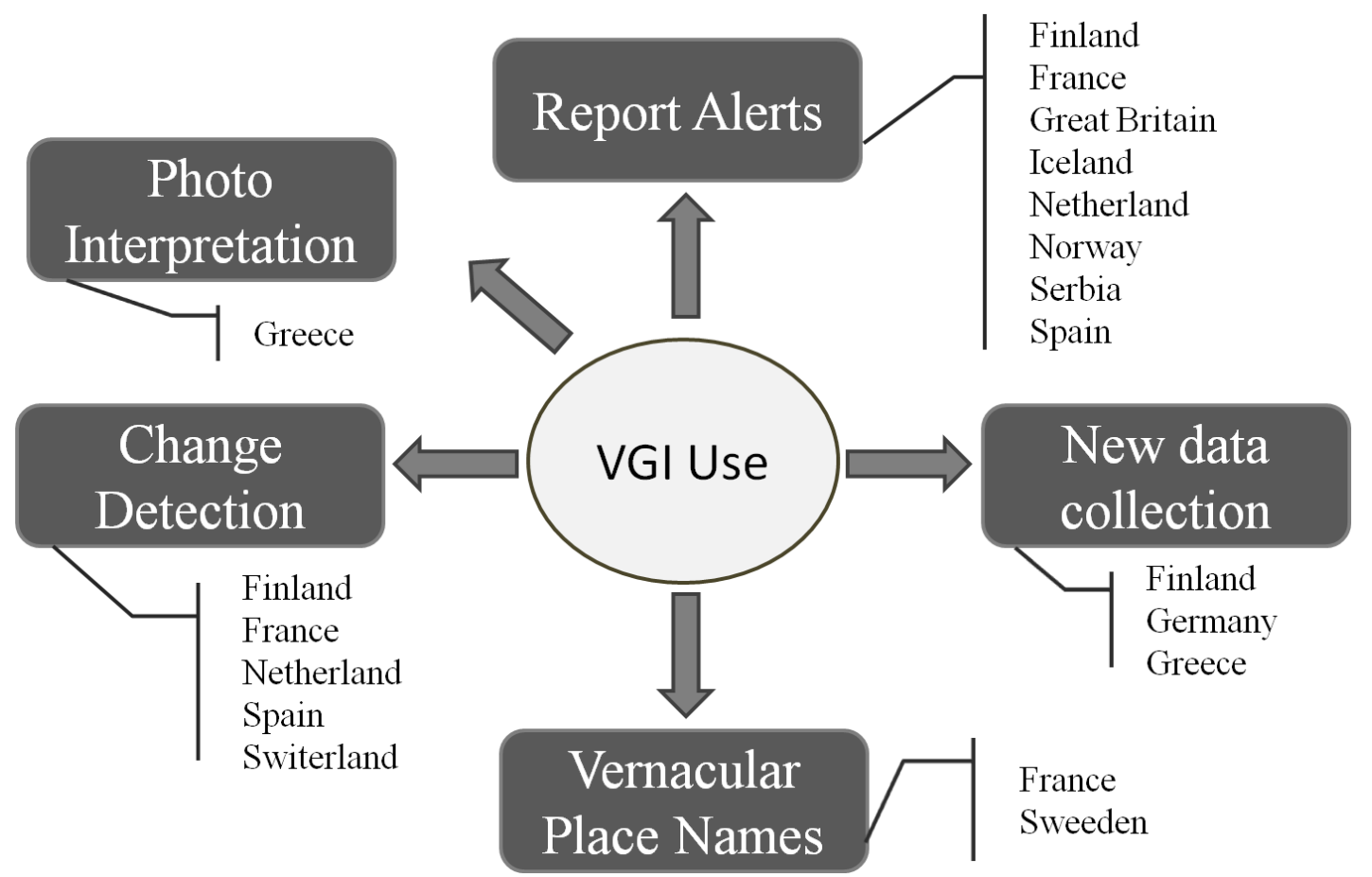

Figure 5. VGI use in the European NMAs 


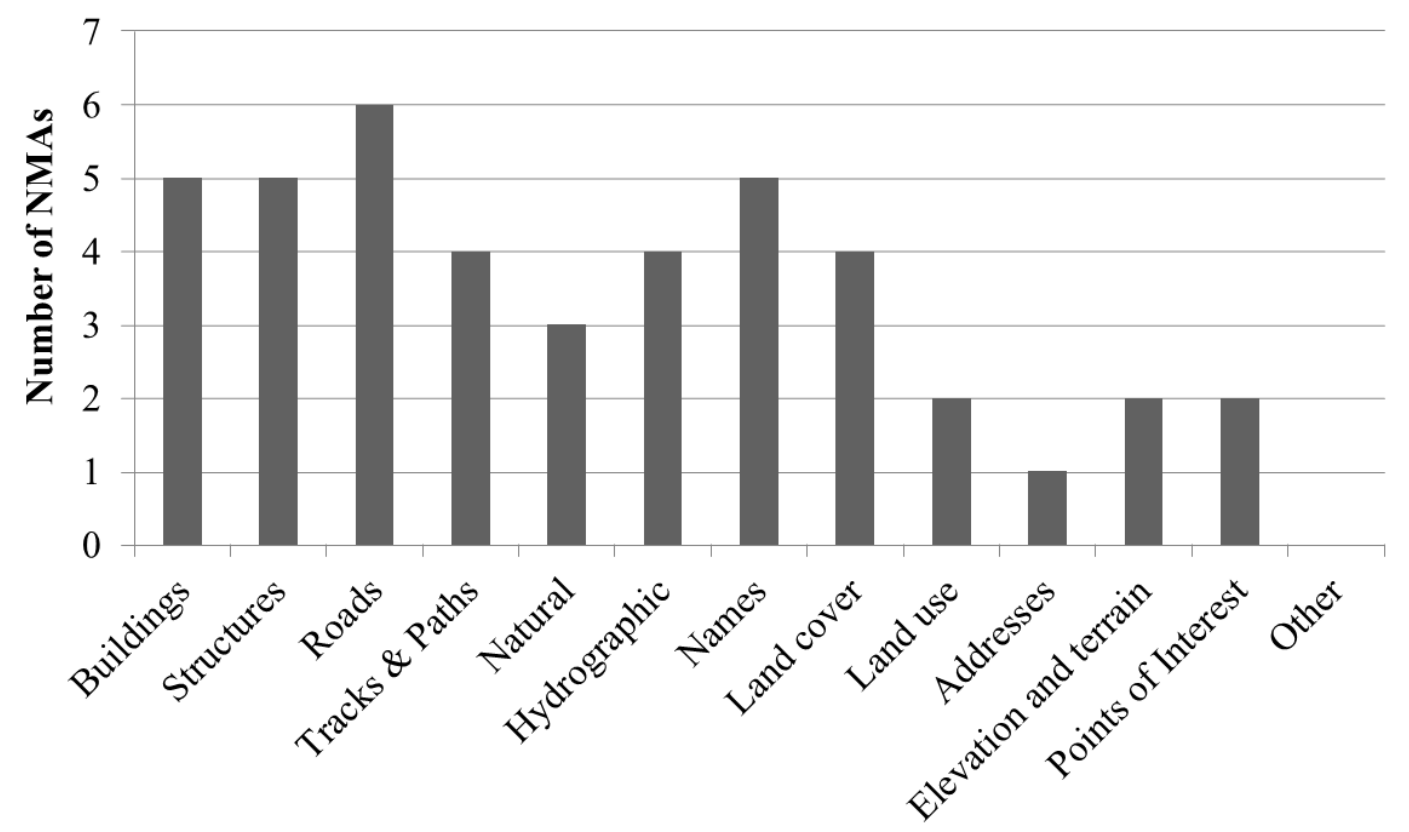

Figure 6. Feature types reported on through VGI 


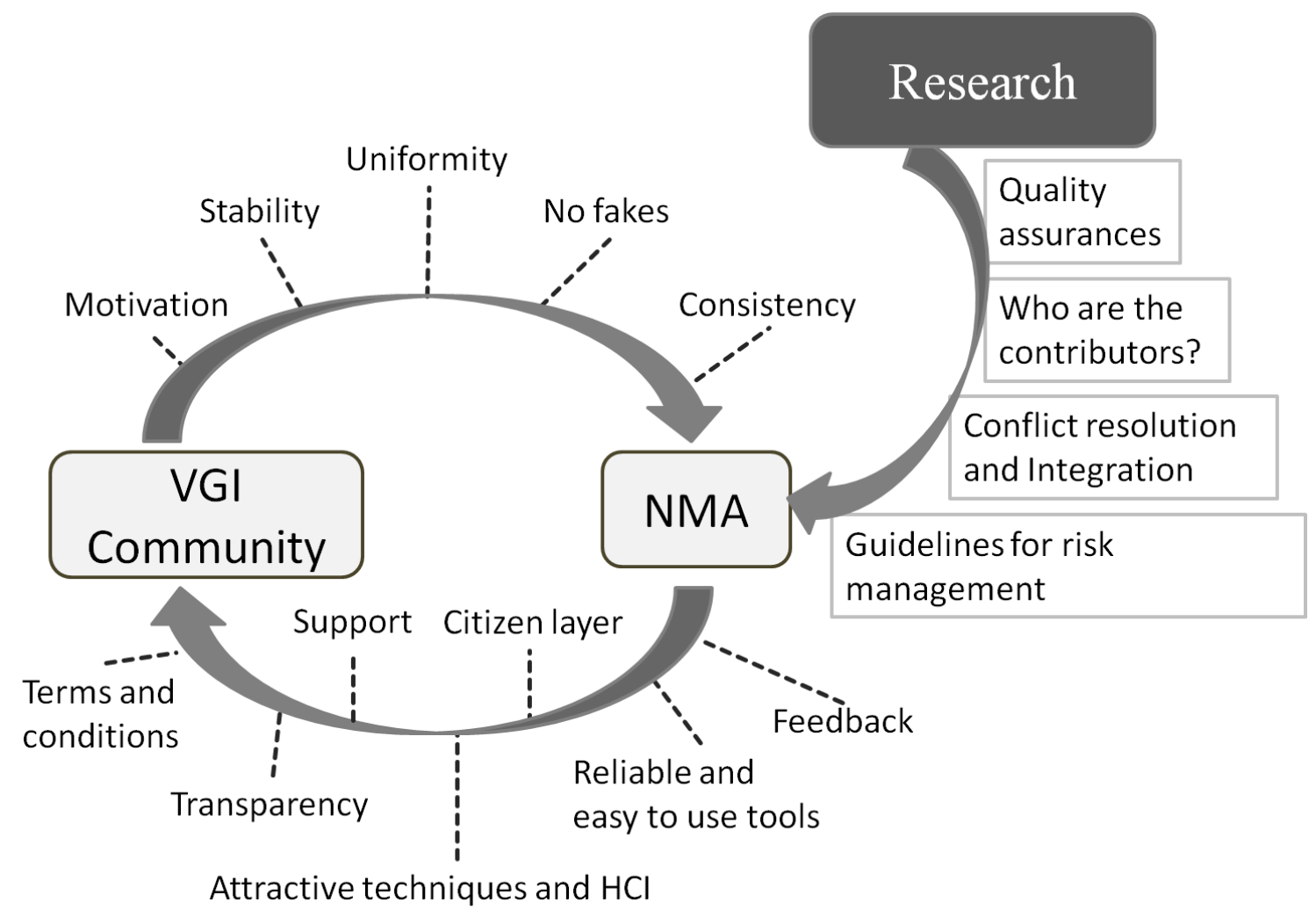

Figure 7. Relationships between NMA, VGI, and Research community 